\title{
Extension Sliding Mode Controller for Maximum Power Point Tracking of Hydrogen Fuel Cells
}

\author{
Meng-Hui Wang, Her-Terng Yau, and Tai-Yuan Wang \\ Department of Electrical Engineering, National Chin-Yi University of Technology, Taichung 41170, Taiwan \\ Correspondence should be addressed to Her-Terng Yau; pan1012@ms52.hinet.net
}

Received 12 May 2013; Accepted 25 June 2013

Academic Editor: Chang-Hua Lien

Copyright ( 2013 Meng-Hui Wang et al. This is an open access article distributed under the Creative Commons Attribution License, which permits unrestricted use, distribution, and reproduction in any medium, provided the original work is properly cited.

Fuel cells (FCs) are characterized by low pollution, low noise, and high efficiency. However, the voltage-current response of an FC is nonlinear, with the result that there exists just one operating point which maximizes the output power given a particular set of operating conditions. Accordingly, the present study proposes a maximum power point tracking (MPPT) control scheme based on extension theory to stabilize the output of an FC at the point of maximum power. The simulation results confirm the ability of the controller to stabilize the output power at the maximum power point despite sudden changes in the temperature, hydrogen pressure, and membrane water content. Moreover, the transient response time of the proposed controller is shown to be faster than that of existing sliding mode (SM) and extremum seeking (ES) controllers.

\section{Introduction}

With growing international concern regarding the depletion of the world's natural resources and the effects of global warming, the need for renewable energy sources has emerged as a critical issue in recent years. Among the various clean energy technologies available, for example, wind power, solar energy, and fuel cells (FCs), FCs are particularly attractive due to their low pollution, virtually silent running, simple maintenance, long service lives, and so on. Moreover, FCs have a generating efficiency of approximately $40-60 \%$; with an overall efficiency of more than $80 \%$ being possible through their integration with cogeneration technologies. Thus, as the cost of FC materials continues to decrease, the commercialization of FCs for stationary and standalone applications is becoming increasingly attractive $[1,2]$.

The output voltage of an FC depends on the cell temperature, the air and hydrogen pressure, the oxygen partial pressure, and the membrane water content [3]. Notably, FCs have a nonlinear voltage-current characteristic, and thus there exists just one unique operating point which maximizes the output voltage and power under a particular set of operating conditions. Accordingly, a requirement exists for maximum power point tracking (MPPT) algorithms capable of controlling the stack current and fuel flow in such a way as to maximize the cell efficiency and output power under variable operating conditions [3].

Many MPPT methods for photovoltaic systems have been proposed, including Hill-climbing/Perturb and Observe $(\mathrm{P} \& \mathrm{O})$, incremental conductance, fractional open-circuit voltage, fractional short-circuit current, fuzzy logic control (FLC), neural networks (NNs), ripple correlation control, current sweep, DC-Link capacitor droop control, load current/load voltage maximization, and sliding mode control (SMC) [4]. Such methods provide an effective means of solving the MPPT problem, but vary widely in terms of their complexity, implementation hardware, convergence speed, and sensed parameters [4]. Various MPPT algorithms have been presented for maximizing the output power of FC modules, for example, $\mathrm{P} \& \mathrm{O}$ [5-9], adaptive MPPT control [10], motocompressor control [11], adaptive FLC control [12], resistance matching [13], voltage and current based MPPT [14], and adaptive extremum seeking (ES) control [15].

As discussed previously, the FC efficiency and output power are highly sensitive to changes in the operating conditions. Previous studies have proposed reducing the effects of system disturbances on the FC performance by means of sliding mode (SM) [16] or fuzzy sliding mode (FSM) [17] 
controllers. In the present study, the output voltage of an FC is stabilized at the point of maximum power by means of an SM controller based on extension theory. The performance of the proposed extension sliding mode (ESM) controller is evaluated and compared with that of existing MPPT control schemes by means of Matlab/Simulink simulations.

\section{Mathematical Model of Fuel Cell}

Figure 1 presents a schematic illustration of the FC power generation process. As shown, the FC is fed with hydrogen and oxygen, and an electrical current is generated as a result of the subsequent oxidation/reduction reactions at the anode and cathode electrodes, respectively. The relevant chemical reactions are as follows $[18,19]$ :

$$
\begin{aligned}
& \text { Anode }: \mathrm{H}_{2} \longrightarrow 2 \mathrm{H}^{+}+2 \mathrm{e}^{-} \\
& \text {Cathode }: \mathrm{O}_{2}+4 \mathrm{H}^{+}+4 \mathrm{e}^{-} \longrightarrow 2 \mathrm{H}_{2} \mathrm{O} .
\end{aligned}
$$

In developing the proposed MPPT control scheme, the present study considers the hydrogen FC developed by Ballard Power Systems (Canada). For a single FC, the output voltage is given as

$$
V_{\mathrm{FC}}=E_{n}-V_{\mathrm{act}}-V_{\mathrm{ohmic}}-V_{\text {con }},
$$

where $E_{n}$ is the thermodynamic reversible voltage exported from the FC and has the form

$$
\begin{aligned}
E_{n}= & 1.229-8.5 \times 10^{-4}(T-298.15) \\
& +4.31 \times 10^{-5} T \ln \left(P_{\mathrm{H}_{2}} \sqrt{P_{\mathrm{O}_{2}}}\right),
\end{aligned}
$$

in which $P_{\mathrm{H}_{2}}$ and $P_{\mathrm{O}_{2}}$ are the hydrogen and oxygen pressures, respectively, and $T$ is the operating temperature.

$V_{\text {act }}$ in (3) is the activation overvoltage, that is, the combined cathode and anode activation overvoltage, and is given as

$$
V_{\mathrm{act}}=-\left(\delta_{1}+\delta_{2} T+\delta_{3} T \ln \mathrm{C}_{\mathrm{O}_{2}}+\delta_{4} T \ln I_{\mathrm{FC}}\right),
$$

where $\delta_{n}(n=1 \sim 4)$ are parametric coefficients, and $\mathrm{C}_{\mathrm{O}_{2}}$ is the concentration of dissolved oxygen at the gas/liquid interface and is computed as

$$
\mathrm{C}_{\mathrm{O}_{2}}=\frac{P_{\mathrm{O}_{2}}}{5.08 \times 10^{6} \times e^{(-408 / T)}} .
$$

$V_{\text {ohmic }}$ in (3) is the ohmic overvoltage, that is, the voltage loss within the FC resulting from the resistance of the various cell components and interconnects; that is,

$$
V_{\text {ohmic }}=I_{\mathrm{FC}}\left(R_{M}+R_{C}\right) \text {, }
$$

where $R_{C}$ denotes that the resistance contacting and the electron stream is constant and $R_{M}$ is the impedance of the proton exchange membrane; that is,

$$
R_{M}=\frac{\left(\rho_{M} \times l\right)}{A}
$$

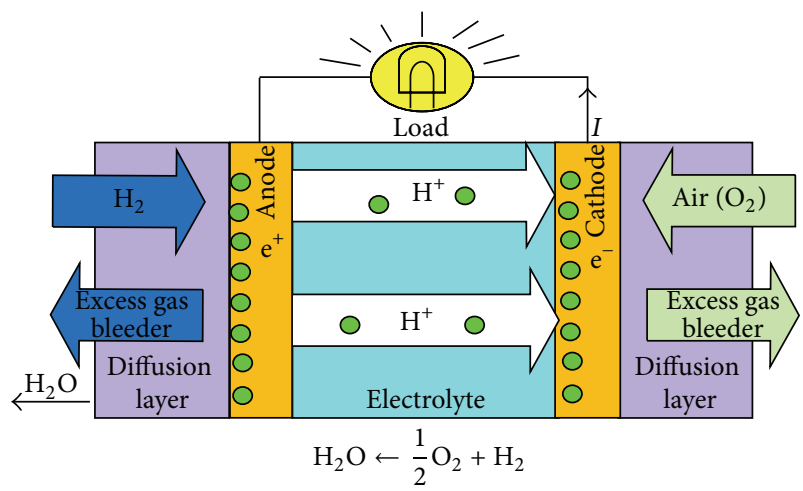

FIGURE 1: FC power generation process.

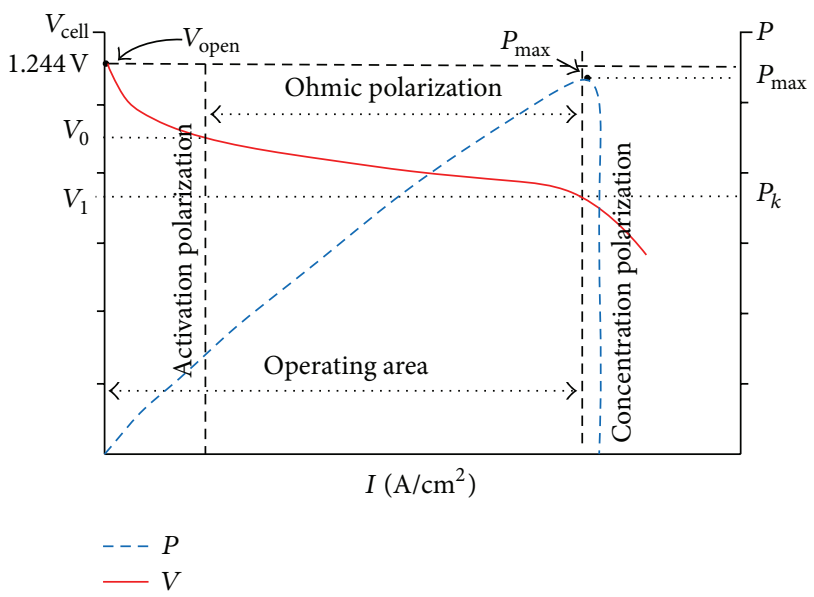

FiguRE 2: Characteristic curve of Ballard FC.

in which $A$ is the cell reaction area, $l$ is the membrane thickness, and $\rho_{M}$ is the membrane resistance coefficient given as

$$
\rho_{M}=\frac{181.6\left[1+0.03 J+0.062(T / 303)^{2}(J)^{2.5}\right]}{[G-0.634-3 J] \exp [4.18(1-303 / T)]} .
$$

Note that in (9), $G$ is the membrane water content and $J$ is the current density; that is,

$$
J=\frac{I_{\mathrm{FC}}}{A} .
$$

Finally, $V_{\text {con }}$ in (3) is the concentration overvoltage resulting from diffusion-limited mass transfer and is given as

$$
V_{\text {con }}=-\frac{R T}{n F} \ln \left(1-\frac{J}{J_{\max }}\right)=-B \cdot \ln \left(1-\frac{J}{J_{\max }}\right),
$$

where $R$ is the universal gas constant, $F$ is Faraday's constant, $J_{\max }$ is the maximum current density, and $B=R T / n F$.

For an FC cell stack comprising $N$ fuel cells, the output power is equal to

$$
P_{\text {stack }}=N V_{\mathrm{FC}} \times I_{\mathrm{FC}} .
$$

As shown in (3)-(12), the output power of an FC varies in accordance with changes in the operating temperature, 


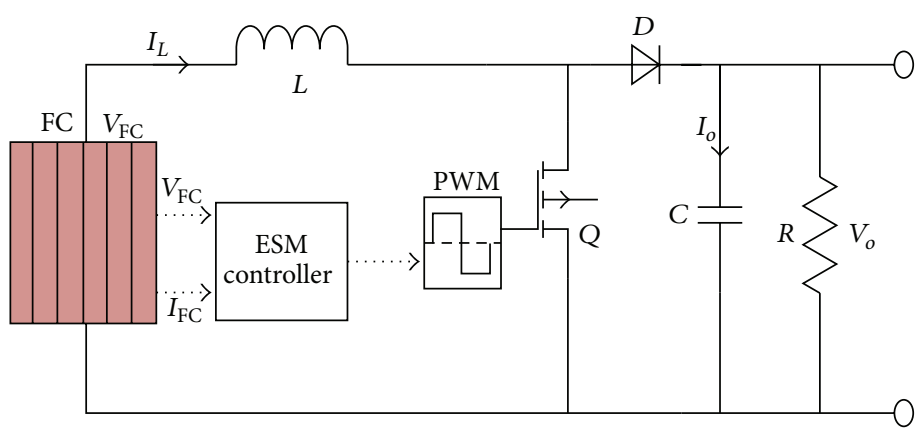

FIGURE 3: Schematic diagram of proposed FC system.

hydrogen pressure, reaction area, and membrane water content, respectively. Figure 2 presents the characteristic curve of the Ballard FC considered in the present study. As shown, in the ideal state, the open-circuit voltage of the FC is equal to approximately $1.244 \mathrm{~V}$ for any load current condition. In practice, however, the voltage drops with an increasing load due to a polarization effect. Thus, as described in the previous section, the present study proposes an SM control scheme based on extension theory to stabilize the output power of the FC at the point of maximum power.

\section{Overall Design of Maximum Power Point Tracking Controller}

Figure 3 illustrates the functional architecture of the proposed FC/control system. As shown, the main components include the FC, the extension sliding mode (ESM) controller, a DC-DC boost convertor, and a resistive load. In the proposed approach, the output voltage and current signals of the FC are taken as inputs to the ESM controller, which then regulates the DC-DC boost converter in such a way as to maintain the output power of the FC at the maximum power point by means of a pulse-width modulation (PWM) switching scheme [20].

The details of the PWM switching scheme are as follows.

State 1. When switch $Q$ is on, the diode $D$ is cut off, and the input voltage flows through the inductor $L$ directly. Thus, the inductive current $I_{L}$ increases and capacitor $C$ is required to supply energy to the load. As a result, current $I_{L}$ flows through the switch to form a loop. The corresponding voltage and current equations are as follows:

$$
\begin{aligned}
& \dot{I}_{L\left(Q_{-} \text {on }\right)}=\frac{V_{\mathrm{FC}}}{L}, \\
& \dot{V}_{\text {o(Q_on })}=\frac{-V_{o}}{C R} .
\end{aligned}
$$

State 2. When switch $Q$ is off, the diode $D$ is switched on. Thus, the energy stored in the inductor $L$ is discharged to the output end and $I_{L}$ reduces toward zero. The relevant current and voltage equations are as follows:

$$
\begin{aligned}
& \dot{I}_{L\left(\mathrm{Q}_{-} \text {off }\right)}=\frac{V_{\mathrm{FC}}}{L}-\frac{V_{o}}{L}, \\
& \dot{V}_{o\left(\mathrm{Q}_{-} \text {off }\right)}=\frac{I_{L}}{L}-\frac{V_{o}}{C R} .
\end{aligned}
$$

Combining (13)-(16), the current and voltage equations for the PWM controller are as follows:

$$
\begin{aligned}
& \dot{I}_{L}=(U-1) \times \frac{V_{o}}{L}+\frac{V_{\mathrm{FC}}}{L}, \\
& \dot{V}_{o}=(1-U) \times \frac{I_{L}}{C}-\frac{V_{o}}{C R},
\end{aligned}
$$

where $U$ is the duty cycle, $V_{o}$ is the output voltage, and $I_{L}$ is the inductor current.

\section{Proposed Extension Sliding Mode Controller}

In the sliding mode control (SMC) method, the control rules are designed in such a way that the system slides continuously along a sliding surface comprising the boundaries of multiple control structures. In the MPPT control system developed in this study, the sliding surface is set as $d p / d I=0$, and the maximum power point is tracked via the appropriate manipulation of the DC-DC converter by the ESM controller $[21,22]$.

4.1. Mathematical Derivation. For the proposed ESM control scheme, the maximum power point occurs when $d p / d I=0$. In other words, the sliding surface to be controlled is defined as follows:

$$
S=\frac{d P}{d I_{\mathrm{FC}}}
$$

Substituting $P=I V$ into (18) and simplifying, the sliding surface is obtained as

$$
S=\frac{d I_{\mathrm{FC}} V_{\mathrm{FC}}}{d I_{\mathrm{FC}}}=V_{\mathrm{FC}}+I_{\mathrm{FC}} \cdot \frac{\partial V_{\mathrm{FC}}}{\partial I_{\mathrm{FC}}},
$$


where

$$
\begin{aligned}
& \frac{\partial V_{\mathrm{FC}}}{\partial I_{\mathrm{FC}}}=\frac{\partial}{\partial I_{\mathrm{FC}}} E_{n}-\frac{\partial}{\partial I_{\mathrm{FC}}} V_{\mathrm{act}}-\frac{\partial}{\partial I_{\mathrm{FC}}} V_{\mathrm{ohmic}}-\frac{\partial}{\partial I_{\mathrm{FC}}} V_{\mathrm{con}}, \\
& \frac{\partial}{\partial I_{\mathrm{FC}}} E_{n}=0 \\
& \frac{\partial}{\partial I_{\mathrm{FC}}} V_{\mathrm{act}}=-\frac{\delta_{4} T}{I_{\mathrm{FC}}}, \\
& \frac{\partial}{\partial I_{\mathrm{FC}}} V_{\mathrm{ohmic}}=\left(R_{M}+R_{\mathrm{C}}\right)+I_{\mathrm{FC}} \times \frac{\partial R_{M}}{\partial I_{\mathrm{FC}}}, \\
& \frac{\partial R_{M}}{\partial I_{\mathrm{FC}}}=\frac{l}{A_{C}} \times \frac{\partial \rho_{M}}{\partial I_{\mathrm{FC}}}, \\
& \frac{\partial}{\partial I_{\mathrm{FC}}} \rho_{M}=M \times\left(\frac{0.03}{A}+N \times 2.5 \times J^{1.5} \times \frac{1}{A}-O\right), \\
& M=\frac{181.6}{\left[G-0.634-3\left(I_{\mathrm{FC}} / A\right)\right] \exp [4.18(1-303 / T)]}, \\
& N=0.062 \times\left(\frac{T}{303}\right)^{2} \\
& O=\frac{-3\left(1+0.03 J+N \times J^{2.5}\right)}{(G-0.634-3 J)}, \\
& \frac{\partial V_{\mathrm{con}}}{\partial I_{\mathrm{FC}}}=B \times \frac{1}{A J_{\max }-I_{\mathrm{FC}}} \text {. }
\end{aligned}
$$

As described previously, the aim of the ESM controller is to track the maximum power point, that is, to drive the system toward the following sliding surface:

$$
S=V_{\mathrm{FC}}+I_{\mathrm{FC}} \cdot \frac{\partial V_{\mathrm{FC}}}{\partial I_{\mathrm{FC}}}=0
$$

From Figure 3, it is seen that $I_{L}=I_{\mathrm{FC}}$. Thus, the PWM control rule required to satisfy (30) can be expressed as the following (31) for the system dynamics to remain on the switching surface

$$
\dot{S}=\frac{\partial S}{\partial I_{\mathrm{FC}}} \frac{\partial I_{\mathrm{FC}}}{\partial t}=\frac{\partial S}{\partial I_{\mathrm{FC}}} \times\left[(U-1) \times \frac{V_{o}}{L}+\frac{V_{\mathrm{FC}}}{L}\right]=0
$$

In the ideal case, $\dot{I}_{\mathrm{FC}}=0$. Thus, the duty cycle in (31) has the form

$$
U_{\mathrm{eq}}=1-\frac{V_{\mathrm{FC}}}{V_{o}} .
$$

The duty cycle $U$ must have a value in the range of 0 to 1 . Thus, in implementing the proposed ESM control scheme, the duty cycle is derived as follows:

$$
U= \begin{cases}1 & U_{\mathrm{eq}}+\eta S \geq 0 \\ U_{\mathrm{eq}}+\eta S & 0<U_{\mathrm{eq}}+\eta S<1 \\ 0, & U_{\mathrm{eq}}+\eta S \leq 0\end{cases}
$$

where $\eta>0$ is the control gain which is to be determined. In previous studies, the control gain required to minimize steady-state chattering was determined using a fuzzy sliding mode scheme. By contrast, in the present study, the optimal value of $\eta$ is determined using extension theory.

4.2. Proposed Gain Tuning Method. Extension theory was originally proposed by Cai in 1983 and contains two main disciplines, namely, matter-element theory and extension set theory $[23,24]$.

(1) Definition of Matter-Element. Defining the name of the matter as $N$, the characteristics of the matter as $C$, and the value of $C$ as $U$, the matter-element can be expressed as follows:

$$
R=\left\{\begin{array}{ccc}
N & C_{1} & U_{1} \\
& \vdots & \vdots \\
& C_{n} & U_{n}
\end{array}\right\}
$$

where $C=\left[c_{1}, c_{2}, \ldots, c_{n}\right]$ is a characteristic vector and $U=$ $\left[u_{1}, u_{2}, \ldots, u_{n}\right]$ is the value vector of $C$.

(2) Definition of Extension Set. Let $\Omega$ be the universe of discourse. The extension set $\widetilde{A}$ on $\Omega$ is then defined as the following set of ordered pairs:

$$
\widetilde{A}=\{(x, y) \mid x \in \Omega, y=K(x) \in(-\infty, \infty)\},
$$

where $y=K(x)$ is referred to as the correlation function for extension set $\widetilde{A}$ and has the form shown in Figure 4.

As shown in Figure $4, K(x)$ maps each element of $\Omega$ to a membership grade between $-\infty$ and $\infty$. The higher the degree of the membership grade, the more the number of elements which belong to the set. It is noted that the particular case of $0 \leq K(x) \leq 1$ corresponds to a normal fuzzy set. Moreover, the condition $K(x) \leq 1$ implies that element $x$ has no chance of belonging to the set. By contrast, the condition $-1<K(x)<0$ represents the extension domain; that is, element $x$ has a chance of belonging to the set.

The gain tuning method proposed in this study can be summarized as follows [10].

Step 1. Let the duty cycle of the PWM switch be redefined as

$$
U= \begin{cases}\eta S, & S \in E \\ U_{\mathrm{eq}}+\eta S, & S \notin E,\end{cases}
$$

where $E$ is the extension field (see Figure 4). Appropriate control laws are designed in the rational region and extension region, respectively, in order to ensure system stability. The extension correlation function and corresponding weights are then calculated in accordance with the defined characteristic values of $S$ and $\dot{S}$, respectively.

Step 2. Partition the unknown matter element into various grade set characteristics, where the number of grade sets is 


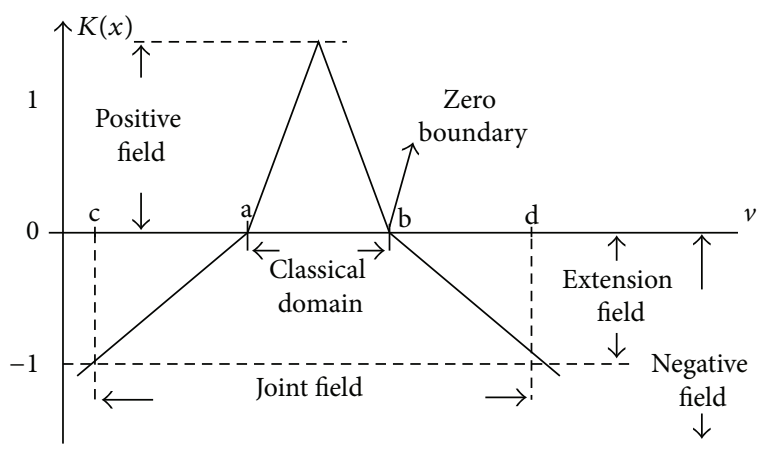

Figure 4: Extended correlation function.

equal to the number of sets in the classical domain and joint domain; that is,

$$
R=\left(N, C_{i}, V_{i}\right)=\left[\begin{array}{ccc}
N & C_{1} & \left\langle a_{1}, b_{1}\right\rangle \\
& C_{2} & \left\langle a_{2}, b_{2}\right\rangle \\
\vdots & \vdots \\
& C_{n} & \left\langle a_{n}, b_{n}\right\rangle
\end{array}\right],
$$

where $N$ is the matter element which is to be divided, $C_{i}$ are the characteristics of the matter element, and $V_{i}$ is the characteristic value range, that is, the distribution range of the $i$ th characteristic. Finally, $a_{i}$ indicates the maximum value of the $i$ th characteristic among the matter element grade sets, while $b_{i}$ denotes the minimum value of the $i$ th characteristic.

Step 3. Assign weights to the various characteristics such that

$$
\sum_{i=1}^{n} \lambda_{i}=1
$$

In the ESM control scheme proposed in the current study, the weightings are determined via the following entropybased approach; that is,

$$
\lambda_{i}=\left[\sum_{i=1}^{n}\left(1-\varsigma \times V_{i}\right)\right]^{-1}, \quad 0<\varsigma<1 .
$$

Step 4. Calculate the degree of association between the data to be measured in accordance with

$$
K\left(x_{i}\right)=\left\{\begin{array}{lc}
\frac{-\rho\left(x_{i}, V_{i}\right)}{\left|V_{i}\right|}, & -1 \leq \rho\left(x_{i}, V_{i}\right) \leq 0 \\
\frac{\rho\left(x_{i}, V_{i}\right)}{\rho\left(x_{i}, V_{t}\right)-\rho\left(x_{i}, V_{i}\right)}, & \text { or } \rho\left(x_{i}, V_{i}\right)<-1 \\
& \text { otherwise, }
\end{array}\right.
$$

where

$$
\begin{aligned}
& \rho\left(x_{i}, V_{i}\right)=\left|x_{i}-\frac{a_{i}+b_{i}}{2}\right|-\frac{b_{i}-a_{i}}{2}, \\
& \rho\left(x_{i}, V_{t}\right)=\left|x_{i}-\frac{c_{i}+d_{i}}{2}\right|-\frac{d_{i}-c_{i}}{2} .
\end{aligned}
$$

TABLE 1: Parameters of fuel cell system and DC-DC converter.

\begin{tabular}{lc}
\hline Parameter & Value \\
\hline$T(\mathrm{~K})$ & 318.15 \\
$P_{\mathrm{H}_{2}}($ atm $)$ & 0.8 \\
$P_{\mathrm{O}_{2}}$ (atm) & 1 \\
Load & $10 \Omega$ \\
Inductance & $800 \mathrm{mH}$ \\
Capacitance & $800 \mu \mathrm{F}$ \\
\hline
\end{tabular}

Step 5. Calculate the relative values of the degree of association of the various grade sets using the normalization equation shown in (42) such that the degree of association of each grade set falls within $\langle 1,-1\rangle$.

$$
K(q)^{*}=\frac{2 K(q)-K(q)_{\min }-K(q)_{\max }}{K(q)_{\max }-K(q)_{\min }} .
$$

Step 6. Determine which grade set the matter element belongs to. If $K(q)^{*}=1$, the degree of correlation is of the evaluation result of type $i$. The probability of other set types is determined according to the degree of association. The outcome of this step is used to identify the gain value $\eta$ which ensures that the output power of the FC tracks the maximum power point.

\section{Simulation Results and Discussion}

The performance of the proposed extension sliding mode (ESM) controller was evaluated by means of a series of Matlab/Simulink simulations based on the integrated model shown in Figure 5. Note that in performing the simulations, the maximum output power of the FC was assumed to be $550 \mathrm{~W}$ and the simulation run time was specified as $10 \mathrm{~s}$. In addition, the matter-element module was set as shown in (43).

The characteristic parameters of the simulated fuel cell system and DC-DC converter are shown in Table 1.

Figure 6 shows the simulation results obtained for the output power of the FC given an operating temperature of $25^{\circ} \mathrm{C}$. Figures 7,8 , and 9 show the simulated response of the controlled FC given step changes in the temperature, hydrogen pressure, and membrane water content from $25^{\circ} \mathrm{C}$ to $60^{\circ} \mathrm{C}, 0.5 \mathrm{~atm}$ to $10 \mathrm{~atm}$, and 10 to 20 , respectively. The results confirm the ability of the proposed ESM control scheme to stabilize the output power of the FC at the point of maximum power despite perturbations in the FC operating conditions. Consider the following:

$$
R=\left(\begin{array}{cc}
\text { sliding } S & \langle 50,90\rangle \\
& \langle 20,50\rangle \\
& \langle 10,20\rangle \\
& \langle 5,10\rangle \\
\langle 1,5\rangle \\
\langle 0.5,1\rangle \\
\langle 0.1,0.5\rangle \\
\langle 0.05,0.1\rangle \\
\langle 0,0.05\rangle
\end{array}\right)
$$




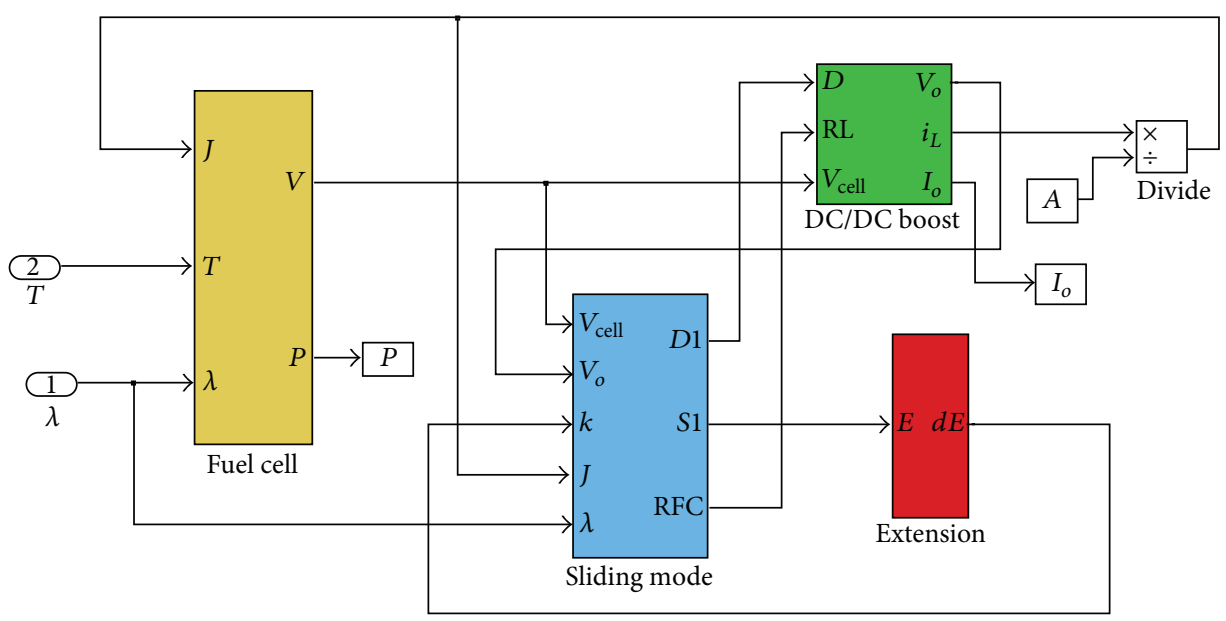

FIGURE 5: Integrated Simulink model of FC and ESM control system.

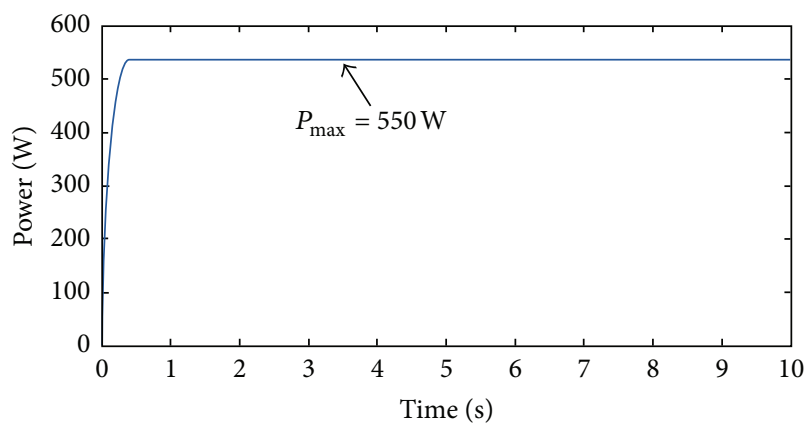

Figure 6: Evolution of FC output power under normal operating conditions.

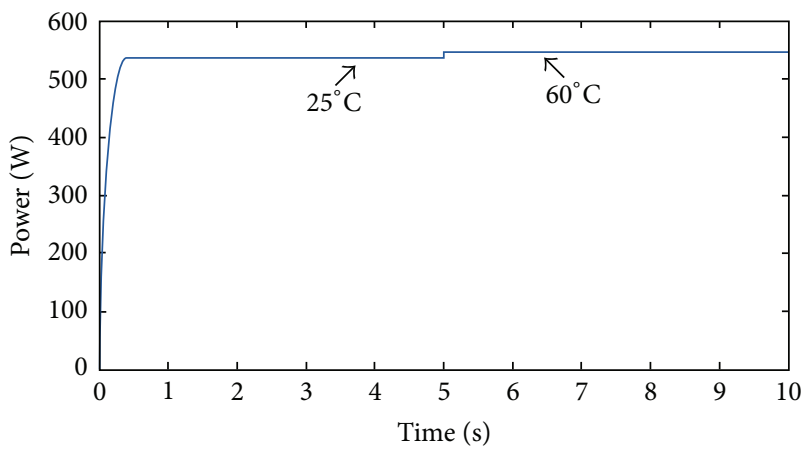

FIGURE 7: FC output power response given step change in operating temperature.

Figure 10 and Table 2 compare the transient and steadystate performance of the FC when controlled by three different schemes, namely, the ESM scheme proposed in the present study, the conventional SM scheme [21], and an extremum seeking (ES) scheme [15]. It is seen in Figure 10 that the ES method yields a slow transient response and a poor steady-state stability. Furthermore, it is seen that while the ESM and SM methods both stabilize the output power at the maximum power point, the transient response of

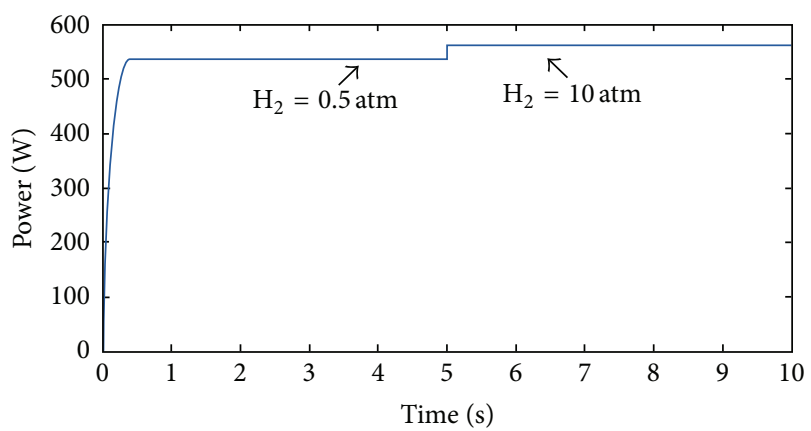

FIGURE 8: FC output power response given step change in hydrogen pressure.

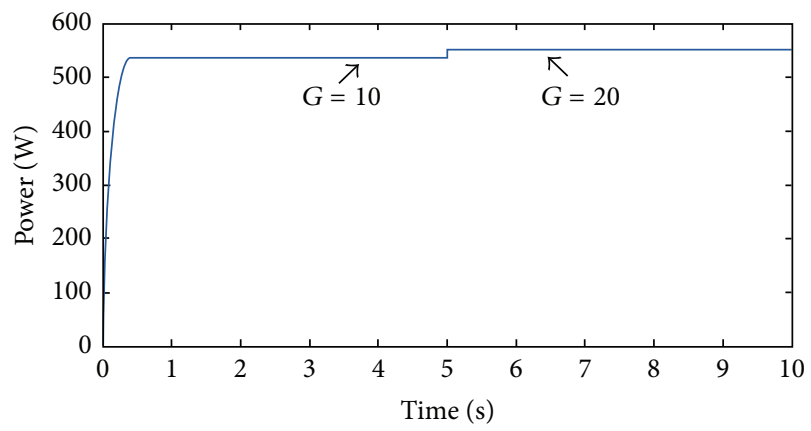

FIGURE 9: FC output response given step change in membrane water content.

the proposed ESM method is faster than that of the traditional SM method.

\section{Conclusions}

A sliding mode (SM) controller based on extension theory has been proposed for stabilizing the output power of a fuel cell (FC) at the maximum power point. In the proposed approach, the sliding mode is used to track the maximum 
TABLE 2: Comparison of different control methods.

\begin{tabular}{lcccc}
\hline & Stable time (sec) & \multicolumn{3}{c}{ Steady error } \\
& & $\Delta P(\mathrm{~W})$ & $\Delta V(\mathrm{~V})$ & $\Delta I(\mathrm{~A})$ \\
\hline $\mathrm{ESM}$ & 0.3 & 0.0 & 0.0 & 0.0 \\
$\mathrm{SM}$ & 0.7 & 0.0 & 0.0 & 0.0 \\
$\mathrm{ES}$ & 3.3 & 12.2 & 2.5 & 4.34 \\
\hline
\end{tabular}

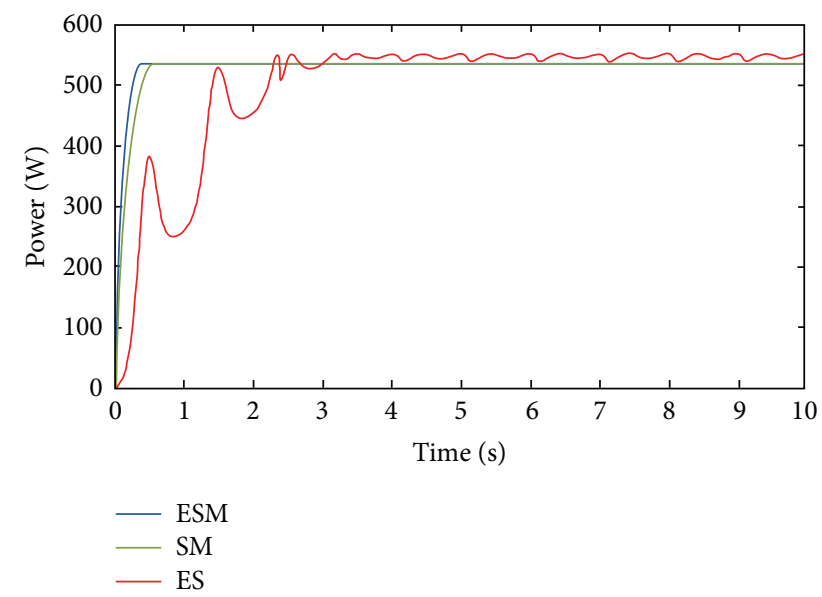

FIGURE 10: Comparison of control performance of ESM, SM, and ES methods.

power point, while extension theory is used to determine the appropriate value of the controller gain which ensures convergence of the controlled system to the sliding surface. The simulation results have shown that the proposed controller successfully stabilizes the output power of the FC at the maximum power point and has a faster transient response time than existing sliding mode (SM) or extremum seeking (ES) control schemes.

\section{Acknowledgment}

This paper was supported by the National Science Council of Taiwan, under Grant NSC-2628-E-167-002-MY3.

\section{References}

[1] C. A. Ramos-Paja, A. Romero, R. Giral, J. Calvente, and L. Martinez-Salamero, "Mathematical analysis of hybrid topologies efficiency for PEM fuel cell power systems design," International Journal of Electrical Power and Energy Systems, vol. 32, no. 9, pp. 1049-1061, 2010.

[2] Y. Hou, B. Wang, and Z. Yang, "A method for evaluating the efficiency of PEM fuel cell engine," Applied Energy, vol. 88, no. 4, pp. 1181-1186, 2011.

[3] J. O. Schumacher, P. Gemmar, M. Denne, M. Zedda, and M. Stueber, "Control of miniature proton exchange membrane fuel cells based on fuzzy logic," Journal of Power Sources, vol. 129, no. 2, pp. 143-151, 2004.

[4] T. Esram and P. L. Chapman, "Comparison of photovoltaic array maximum power point tracking techniques," IEEE Transactions on Energy Conversion, vol. 22, no. 2, pp. 439-449, 2007.
[5] L. N. Khanh, J. Seo, Y. Kim, and D. Won, "Power-management strategies for a grid-connected PV-FC hybrid system," IEEE Transactions on Power Delivery, vol. 25, no. 3, pp. 1874-1882, 2010.

[6] A. Giustiniani, G. Petrone, G. Spagnuolo, and M. Vitelli, "Low-frequency current oscillations and maximum power point tracking in grid-connected fuel-cell-based systems," IEEE Transactions on Industrial Electronics, vol. 57, no. 6, pp. $2042-$ 2053, 2010.

[7] C. A. Ramos-Paja, G. Spagnuolo, G. Petrone, R. Giral, and A. Romero, "Fuel cell MPPT for fuel consumption optimization," in Proceedings of the IEEE International Symposium on Circuits and Systems (ISCAS '10), pp. 2199-2202, June 2010.

[8] M. Dargahi, M. Rezanejad, J. Rouhi, and M. Shakeri, "Maximum power point tracking for fuel cell in fuel cell/battery hybrid systems," in Proceedings of the 12th IEEE International Multitopic Conference (INMIC '08), pp. 33-37, December 2008.

[9] L. Egiziano, A. Giustiniani, G. Petrone, G. Spagnuolo, and M. Vitelli, "Optimization of perturb and observe control of grid connected PEM fuel cells," in Proceedings of the International Conference on Clean Electrical Power (ICCEP '09), pp. 775-781, June 2009.

[10] Z. Zhong, H. Huo, X. Zhu, G. Cao, and Y. Ren, "Adaptive maximum power point tracking control of fuel cell power plants," Journal of Power Sources, vol. 176, no. 1, pp. 259-269, 2008.

[11] M. Becherif and D. Hissel, "MPPT of a PEMFC based on air supply control of the motocompressor group," International Journal of Hydrogen Energy, vol. 35, no. 22, pp. 12521-12530, 2010.

[12] N. Chanasut and S. Premrudeepreechacharn, "Maximum power control of grid-connected solid oxide fuel cell system using adaptive fuzzy logic controller," in Proceedings of the IEEE Industry Applications Society Annual Meeting (IAS '08), pp. 1-6, October 2008.

[13] K. H. Loo, G. R. Zhu, Y. M. Lai, and C. K. Tse, "Development of a maximum-power-point tracking algorithm for direct methanol fuel cell and its realization in a fuel cell/supercapacitor hybrid energy system," in Proceedings of the IEEE International Conference on Power Electronics and ECCE Asia, pp. 1753-1760, June 2011.

[14] M. Sarvi and M. M. Barati, "Voltage and current based MPPT of fuel cells under variable temperature conditions," in Proceedings of the 45th International Universities' Power Engineering Conference (UPEC '10), pp. 1-4, September 2010.

[15] N. Bizon, "On tracking robustness in adaptive extremum seeking control of the fuel cell power plants," Applied Energy, vol. 87, no. 10, pp. 3115-3130, 2010.

[16] S. Abdi, K. Afshar, N. Bigdeli, and S. Ahmadi, "A novel approach for robust maximum power point tracking of PEM fuel cell generator using sliding mode control approach," International Journal of Electrochemical Science, vol. 7, no. 1, pp. 4192-4209, 2012.

[17] F. Qiao, Q. M. Zhu, A. Winfield, and C. Melhuish, "Fuzzy sliding mode control for discrete nonlinear systems," Transactions of China Automation Society, vol. 22, no. 2, pp. 311-315, 2003.

[18] F. Gao, B. Blunier, M. G. Simões, and A. Miraoui, "PEM fuel cell stack modeling for real-time emulation in hardware-in-theloop applications," IEEE Transactions on Energy Conversion, vol. 26, no. 1, pp. 184-194, 2011.

[19] M. A. Laughton, "Fuel cells," Engineering Science and Education Journal, vol. 11, no. 1, pp. 7-16, 2002. 
[20] M. Dargahi, J. Rouhi, M. Rezanejad, and M. Shakeri, "Maximum power point tracking for fuel cell in fuel cell/battery hybrid power systems," European Journal of Scientific Research, vol. 25, no. 4, pp. 538-548, 2009.

[21] V. Utkin, J. Guldner, and J. Shi, Sliding Mode in Electro-Mechanical Systems, Taylor \& Francis, London, UK, 2009.

[22] M. I. A. Orozco, J. R. Vázquez, P. Salmerón, S. P. Litrán, and F. J. Alcántaram, "Maximum power point tracker of a photovoltaic system using sliding mode control," in Proceedings of the International Conference on Renewable Energies and Power Quality (ICREPQ '09), Valencia, Spain, April 2009.

[23] M. Wang, K. Chao, G. J. Huang, and H. Tsai, "Application of extension theory to fault diagnosis of automotive engine," ICIC Express Letters, vol. 5, no. 4, pp. 1293-1299, 2011.

[24] M. H. Wang, Y. K. Chung, and W. T. Sung, "The fault diagnosis of analog circuits based on extension theory," in Emerging Intelligent Computing Technology and Applications, vol. 5754 of ICIC Lecture Notes in Computer Science, pp. 735-744, Springer, Berlin, Germany, 2009. 


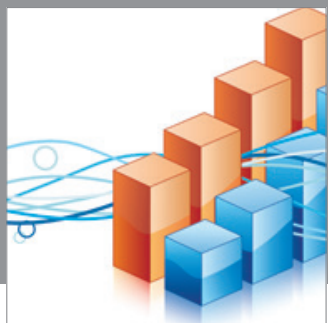

Advances in

Operations Research

mansans

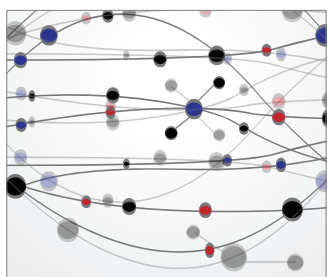

The Scientific World Journal
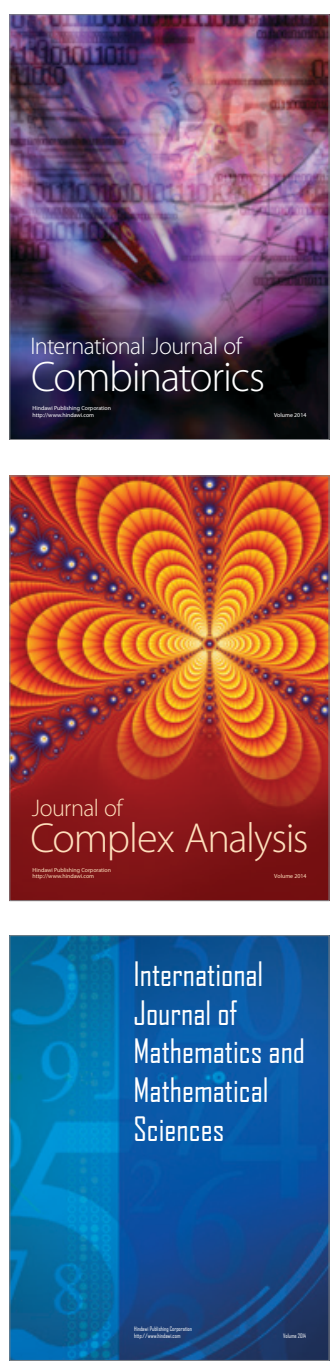
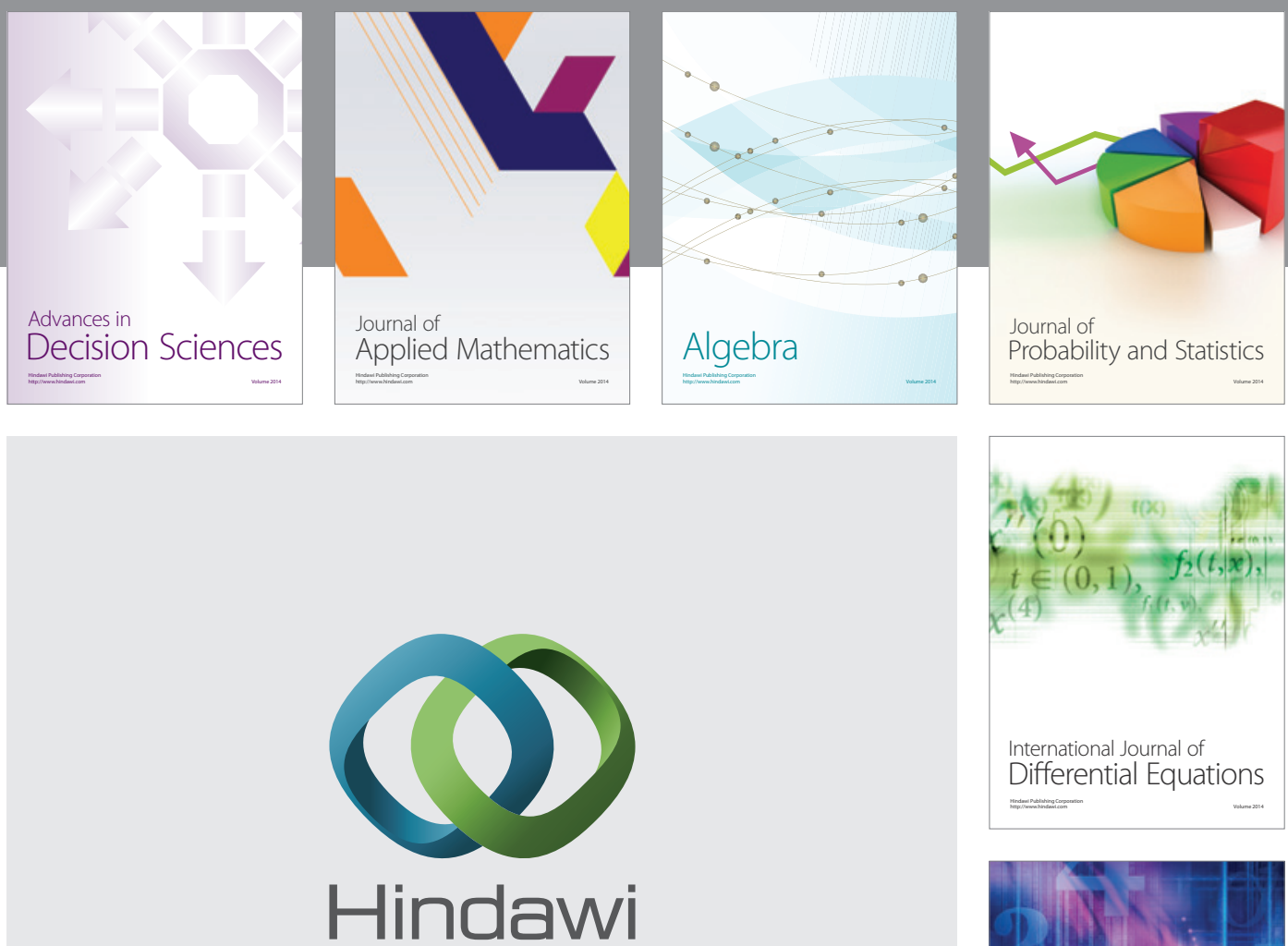

Submit your manuscripts at http://www.hindawi.com
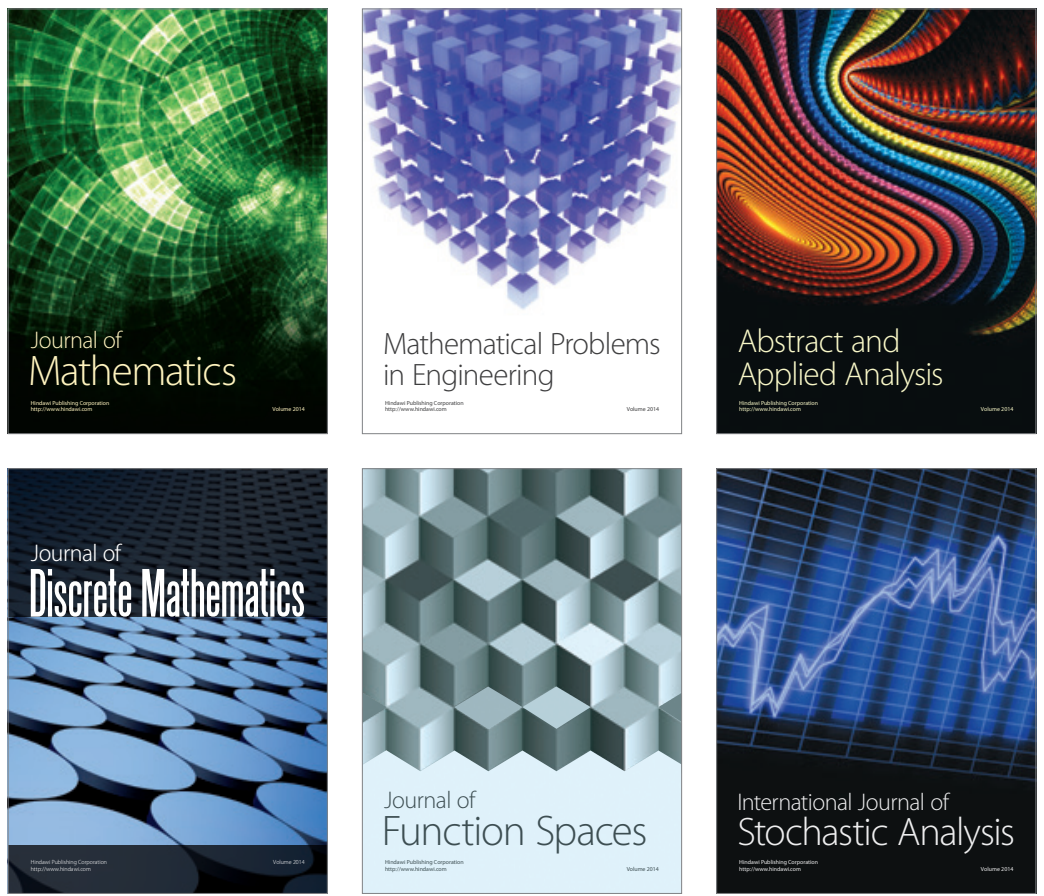

Journal of

Function Spaces

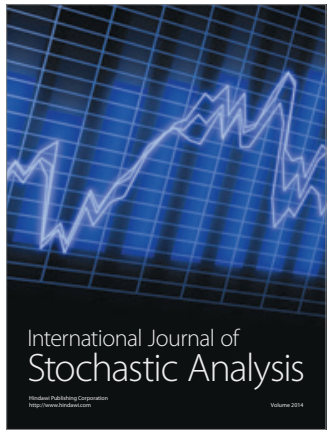

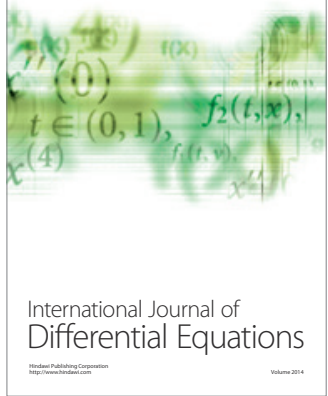
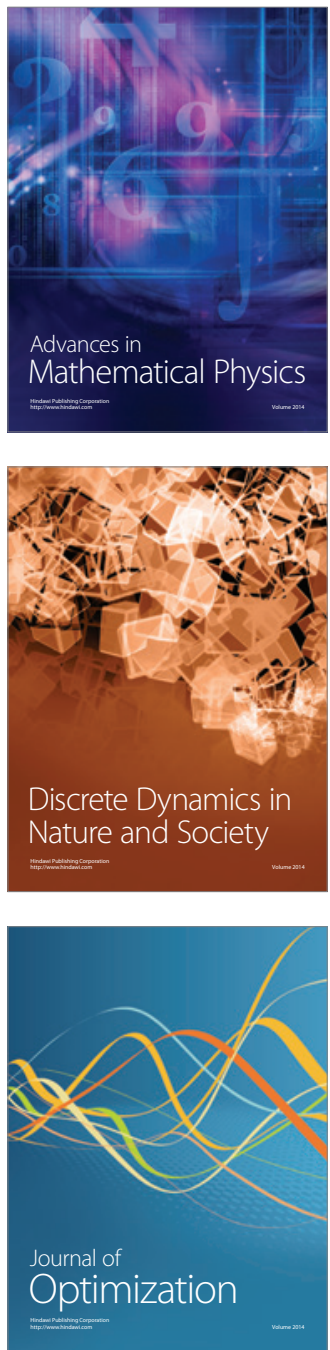